\title{
1826: Forest insect invasion in a changing climate: An overview
}

\section{Tuesday, September 27, 2016 \\ 01:30 PM - 01:45 PM}

Climate change is emerging as the predominant influence on forest ecosystem function and diversity due to its profound effect on many biotic processes. Furthermore, its pervasive nature will likely amplify other important drivers of forest change, including invasive species. The major hypothesized effects of a warming climate on biological invasions in forests are: (1) Altered probability of establishment for novel species, (2) changes in distributional ranges of already established invaders, (3) changes in trophic interactions (4) altered seasonality and voltinism, and (5) changes to outbreak frequency and intensity. Empirical examples of the influence of climate on any of these processes are few and ascribing changes of any aspect of insect invasion to a climatic driver is challenging. First, in all but a few systems, we lack the spatial and temporal resolution to detect climatically driven changes in range or density. Second, we often have a poor understanding of a given species physiological and ecological envelope. Third, the rapid changes in population density and range inherent to invasion may mask any influence of climate on distribution and abundance. The focus of our symposium will be to highlight exemplar systems where a warming climate has been shown to influence invasions in forest insects. We also showcase efforts to develop predictive models that may help to bridge the gap between the few systems where empirical data exists and the vast number of existing and potential invasions where such data is deficient.

doi: 10.1603/ICE.2016.93552

\section{Authors}

\section{Dylan Parry}

State University of New York

\section{Christelle Robinet}

INRA

\section{Patrick C. Tobin}

University of Washington

\section{View Related Events}

Symposium: 319 Symposium: Forest Insect Invasions in a Changing Climate: Mechanisms and Risks

Program: Symposium

Day: Tuesday, September 27, 2016 